\title{
Diplopia and Acute Sixth Nerve Palsy in Hypervitaminosis A - A Case Report and a Review Literature
}

\author{
SAYEEDAANWAR ${ }^{1}$, A.K.M. MATIUR RAHMAN ${ }^{2}$, MANISHA BANNERJEE ${ }^{2}$, AZIMUL HAQUE ${ }^{2}$, \\ MUMTAHINASETU ${ }^{3}$, MD. MOHSIN ${ }^{4}$
}

\section{Introduction:}

Vitamin A is a pivotal biochemical factor required for normal proliferation and differentiation of skin as well as for specialized functions such as vision. It is an important fat soluble vitamin. Its basic molecule is a retinol or vitamin A alcohol. As vitamin A is fat soluble, it is stored in a variable degree in the body, making it more likely to cause toxicity when taken in excess amounts $^{1}$.

The daily recommended dose of vitamin A is $500 \mathrm{mcg}$ in adult, $250-350 \mathrm{mcg}$ in children and $600 \mathrm{mcg}$ in pregnant woman ${ }^{2}$. Acute toxicity of vitamin A occurs within a few hours or days after ingestion of very large amount as a result of accidental overdose or inappropriate therapy. Children often got attracted to vitamin A capsule due to their attractive colours thus accidental ingestion may occur frequently. The estimated toxic dose is about $25,000 \mathrm{lU} / \mathrm{kg}$. A single dose of $>1$ million units of vitamin A can also cause acute toxicity ${ }^{3}$. Chronic toxicity in older children and adults usually develop after doses of $>50,000$ IU/day taken for months ${ }^{4}$. Both acute and chronic toxicity usually cause headache due to increased intracranial pressure. Here we wish to report this case of a 11 years old girl presented with diplopia and $6^{\text {th }}$ nerve palsy, 24 hours after accidental ingestion of a large dose of vitamin A.

\section{Case Report:}

Rekha, a 11 years old girl, $5^{\text {th }}$ issue of nonconsanguinous parents got admitted in pediatric department of Dhaka Medical College Hospital on June,2010 with complaints of history of ingestion of 6 vitamin A capsule (2 lac IU /capsule) 3 days back. She also complained of headache, vomiting, double vision and desquamation of facial skin 24 hours after ingestion of vitamin A capsule. During National vitamin A campaign in her school, she got attracted on colorful vitamin A capsules and took 6 capsules (equivalent to 1.2 million vitamin $A$ ) at a time by herself.
On examination, Rekha was lethargic and mildly anaemic. Her facial skin had desquamation at various places. Her systemic examinations were normal and there was no evidence of focal neurological deficit. She complained of double vision and $6^{\text {th }}$ nerve palsy (Fig-1) was noted. She had bilateral papilloedema.

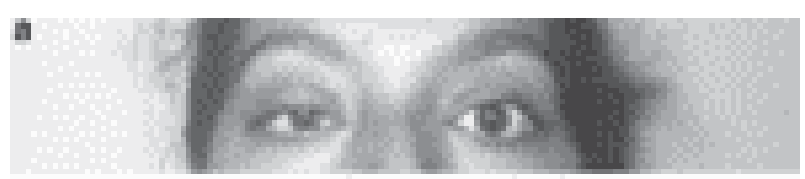

Fig.-1: Eye sign on right eye due to $6^{\text {th }}$ nerve palsy

Complete blood count was normal. Serum calcium level was $8.4 \mathrm{gm} / \mathrm{dl}$.Fundoscopy revealed blurred disc margin of both eye.CSF study was normal and MRI of brain showed normal findings. Serum vitamin A level was not estimated due to lack of facility. We managed her conservatively with Acetazolamide ( $30 \mathrm{mg} / \mathrm{kg} / \mathrm{day}$ ) and prednisolone ( $1.5 \mathrm{mg} / \mathrm{kg} /$ day) for 5 days. 1 day after admission peeling of skin of whole body started (Fig.-2).

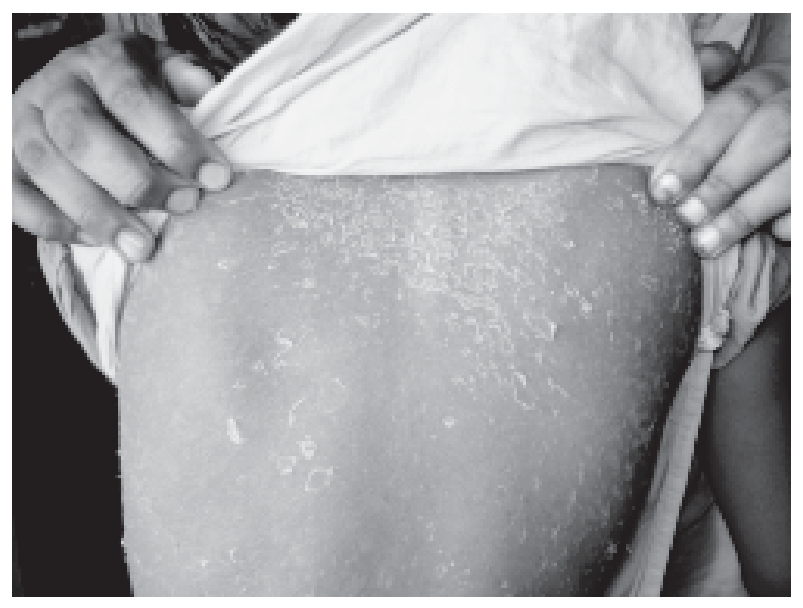

Fig.-2: Desquamation of skin of whole body.

1. Associate Professor, Department of Pediatrics, Dhaka Medical College Hospital, Dhaka

2. Assistant Professor, Department of Pediatrics, Dhaka Medical College Hospital, Dhaka

3. Post Graduate Trainee, Department of Pediatrics, Dhaka Medical College Hospital, Dhaka

4. Assistant Registrer, Department of Pediatrics, Dhaka Medical College Hospital, Dhaka

Correspondence: Dr. Sayeeda Anwar 
She improved with conservative management. Clinical signs and symptoms disappeared after 2 days. We discharged her after 5 days with advice for follow up after 2 weeks.

\section{Discussion:}

Acute vitamin A toxicity generally occurs in children when a single dose $>3,30,000 \mathrm{IU}$ is ingested, although some infants can be adversely affected by single doses as low as $100,000 \mathrm{IU}{ }^{3,5}$. Our case demonstrates acute toxicity developed after a 1.2 million IU of vitamin $A$ at a single dose. The sixth nerve palsy and diplopia occurred presumably from raised CSF pressure. The cause of raised intracranial pressure is not fully understood but may be due to altered CSF resorption or increased production ${ }^{6}$.

Vitamin A toxicity is more common in developed countries in comparison to developing countries. Woman and children of developing countries suffers from vitamin $A$ and other vitamin deficiencies. The benefits of supplementation with high doses of preformed vitamin A twice in a year in combating vitamin A deficiency in woman and children of developing countries are documented ${ }^{7-11}$. Dietary vitamin $A$ is obtained from preformed vitamin A (from animal foods, fortified foods and pharmaceutical supplements) as well as from provitamin A carotenoid from plant sources. In Europe and United states up to $75 \%$ of dietary vitamin $A$ is preformed which is largely derived from multivitamins, fish liver oil and other fortified food such as milk,butter,margarine, breakfast cereals and some snack foods ${ }^{12}$. So, chance of chronic vitamin A toxicity is high there. In developing country only accidental ingestion of high dose can cause acute vitamin A toxicity. Prolonged use of retinoic acid for acne and other skin disorders may cause chronic toxicity ${ }^{4}$.

Vitamin A supplementation efforts were initiated as an immediate action to control vitamin A deficiency while other more long term, sustainable interventions could be developed and implemented. Examples include food fortification, diet diversification and biofortification. Because diet diversification and biofortification typically provide vitamin A carotenoid sources, toxicity will not occur ${ }^{12}$.

\section{References:}

1. Tan KP, Kosuge $\mathrm{K}$, Yang M, Ito S. NRF2 as a determinant of cellular resistance in retinoic acid cytotoxicity. Free Radic Biol Med 2008; 45(12): 1663-73.

2. Collins MD, Mao GE.Tetralogy of retinoids. Annu Rev Pharmacol Toxicol 1999; 39: 399-430.

3. Hathcock JN, Hattan DG, Jenkins MY, McDonald JT, Sundareson PR, Wilkening VL. Evaluation of vitamin A Toxicity. Am J Clin Nutr. 1990; 52(2): 183-202.

4. Baxi SC, Dailey GE. Hypervitaminosis A : A cause of hypercalcaemia West J Med 1982; 137: 429-431.

5. Marie J, see G. Acute hypervitaminosis A of the infant. Am J Dis Child 1953;87:731-736.

6. Becker $\mathrm{NH}$, Sutton $\mathrm{CH}$. Pathologic features of the choroid plexus and cytochemical effects of hypervitaminosis A. Am J Pathol 1963;43:10171030.

7. Sommer A. Uses and misuses of vitamin A. Curr Issues Public Health 1996;2:161-64.

8. Underwood BA. Maternal vitamin A status and its importance in infancy and early childhood. Am J Clin Nutr 1994; 59: 517S-22S.

9. Basu S, Sengupta B, Paladhi PKR. Single megadose vitamin A supplementation of Indian mothers and morbidity in breastfed young infants. Postgrad Med J 2003; 79: 397-402.

10. Roy SK, Islam A, Molla A, Akramuzzaman SM, Jahan F, Fuchs G. Impact of a single megadose of vitamin A at delivery on breast milk of mothers and morbidity of their infants. Eur J Clin Nutr 1997; 51: 302-07.

11. Ross JS, Harvey PWJ. Contribution of breastfeeding to vitamin A nutrition of infants: a simulation model. Bull World Health Organ 2003; 81:80-86.

12. Penniston $\mathrm{KL}$, Tanumihardjo S. The acute and chronic toxic effects of vitamin A. Am J Clin Nutr 2006; 83: 191-201. 